\title{
Bioenergy crops and farmland biodiversity: benefits and limitations are scale-dependant for a declining mammal, the brown hare
}

\author{
Silviu O. Petrovan ${ }^{1,2}$ (D) $\cdot$ John Dixie $^{1} \cdot$ Emma Yapp $^{1} \cdot$ Philip M. Wheeler $^{1,3}$
}

Received: 27 April 2016/Revised: 2 March 2017 / Accepted: 17 April 2017 / Published online: 8 May 2017

(C) The Author(s) 2017. This article is an open access publication

\begin{abstract}
Biomass energy crops are prompting major landuse changes in agricultural and marginal land in an effort to reduce dependency on fossil fuels. Miscanthus $\times$ giganteus, a perennial giant grass, is one of the main such crops in Europe but few studies exist of its interaction with farmland wildlife, particularly mammals. Understanding ecological impacts of bioenergy planting schemes is vital for mitigating potential negative effects on already declining farmland biodiversity and for maximising any benefits from these low-management, structurally diverse crops. We assessed in a mixed farming area in the UK the impact of Miscanthus crops on the brown hare (Lepus europaeus), a widespread but declining farmland species of conservation concern. We intensively radio-tracked hares in Miscanthus blocks of contrasting size and analysed hare diet for evidence of the consumption of Miscanthus. Home ranges differed starkly averaging 10.5 versus 49.6 ha in the small and the large Miscanthus blocks, respectively. Despite entirely avoiding the crop as food, hares appeared able to exist and even thrive in areas planted with Miscanthus
\end{abstract}

Electronic supplementary material The online version of this article (doi:10.1007/s10344-017-1106-5) contains supplementary material, which is available to authorized users.

Silviu O. Petrovan

sop21@cam.ac.uk

1 Centre for Environmental and Marine Sciences, University of Hull, Filey Road, YO11 3AZ Scarborough, UK

2 Present address: Conservation Science Group, Department of Zoology, University of Cambridge, The David Attenborough Building, CB2 3QZ Cambridge, UK

3 Present address: School of Environment, Earth and Ecosystem Sciences, The Open University, Walton Hall, MK7 6AA Milton Keynes, UK though their populations may be significantly limited by reduced food availability and increased energy use where dense Miscanthus is planted over a wide area. As a component of a mixed farming landscape, Miscanthus may provide biodiversity benefits by increasing spatial heterogeneity and refuge areas for declining farmland species like brown hares but any effect is likely to be strongly scale-dependant.

Keywords Bioenergy crops $\cdot$ Farmland biodiversity $\cdot$ Habitat use $\cdot$ Brown hare $\cdot$ Lepus europaeus

\section{Introduction}

The rapid expansion of bioenergy crops and their relationship with farmland biodiversity in temperate climates have generated increasing interest and concern in recent years (Semere and Slater 2007; Pedroli et al. 2013; Everaars et al. 2014; Bourke et al. 2014), particularly given that biodiversity in such areas has declined markedly for decades due to agricultural intensification (Benton et al. 2002; Tscharntke et al. 2012). Second-generation biomass energy crops offer intriguing opportunities to improve spatial and structural heterogeneity in agro-ecosystems by providing areas of tall perennial crops with low mechanical and chemical input (Bellamy et al. 2009; Bourke et al. 2014). Equally, the theoretical potential for total area occupied by biomass energy crops (principally Miscanthus and short-rotation coppice willow) of between 0.72 and $2.80 \mathrm{Mha}$ in the UK alone (DECC 2012) is sufficient to generate significant impacts and land-use conflicts with both food production and farmland biodiversity. Given their novelty, much remains unknown on the specific impacts of bioenergy crops on most taxonomic groups but, where evaluated, impacts depended on the type of planted crop and the crop or land-use it replaces as well as the area it occupies, planting structure and patchiness (for a review, see Dauber et al. 
2015). While there is a general scarcity of data in this area, previous research on ecological effects of such crops has focused on birds, plants or invertebrates and remarkably little is currently known about the impacts of bioenergy crops on mammals, particularly medium- to large-bodied species. This is despite the fact that medium and large mammals in Europe include both threatened species of conservation concern and abundant species such as deer, which can have significant economic and biodiversity effects (Côté et al. 2004). Moreover, while previous studies on the effects of biomass energy crops on biodiversity have looked at patterns in occurrence of multiple species, there have been no detailed investigations of the mechanisms by which species interact with these crops, something which is vital if crop production and biodiversity conservation are to be managed jointly.

The tall, Asian perennial grass Miscanthus $\times$ giganteus (Miscanthus), a triploid hybrid, is the most planted biomass energy crop in much of Europe including the UK, where over 7000 ha was planted with this crop by 2013 (Defra, Government Statistical Service 2014). We focused on the impact of Miscanthus crops on the brown hare (Lepus europaeus), a declining farmland species of significant commercial hunting interest in Europe and a priority species for conservation in the UK. While the exact causes of the brown hare decline in Europe are complex, agricultural intensification manifested through the lack of suitable resting areas, decreased food availability, increased energy expenditure and the general increase of farmland homogeneity appears to be the primary driver (Vaughan et al. 2003; Smith et al. 2005). Hares need to access a range of fields for feeding depending on the season and crop types and use small areas of structurally tall vegetation such as blocks of woodland and field margins for daytime resting (Petrovan et al. 2013). Given the higher abundance of some farmland birds, invertebrates and small mammals in Miscanthus crops in comparison to adjacent farmland (Clapham 2011), this crop could offer increased heterogeneity and areas of refuge for hares, replacing lost habitat diversity. Conversely, if avoided by hares, it might displace them from areas of previously suitable habitat. We therefore aimed to assess hares' use of Miscanthus crops using intensive multi-season radio-tracking and diet analysis. We compared foraging (active) and resting (inactive) periods of animals in different Miscanthus blocks corresponding to an area substantially smaller than (by around 65\%) and larger than (by around 30\%) typical hare home ranges. Our aim was to understand to what extent Miscanthus crops could fulfil habitat requirements for hares.

\section{Methods}

\section{Study site}

We assessed brown hare use of Miscanthus crops in an area of flat mixed farming comprising multiple farms and located in a mixed pasture and arable farming lowland landscape in North
Yorkshire, England (54 $\left.12^{\prime} \mathrm{N}, 0^{\circ} 30^{\prime} \mathrm{W}\right)$. Habitat surveys were undertaken each season and fields and habitats were digitised using 1:10,000 Ordinance Survey field maps (Edina, Digimap, http://edina.ac.uk/digimap) and ArcGIS 10.2 software (ESRI 2014). Several fields of various sizes of mature commercial Miscanthus crops for energy production had been in place for 4-5 years at the time of the study, mostly replacing semi-improved grassland and areas where crops were failing. Two areas with Miscanthus fields, separated by over $1 \mathrm{~km}$, were chosen for the study. One area (hereafter the 'Large block') comprised three large contiguous Miscanthus fields (areas $=8.6,8.7,15.2 \mathrm{ha}$, total $32.5 \mathrm{ha}$ ), surrounded by improved grassland pastures, wheat and barley fields, while the second (the 'Small block') was a single field ( $7.8 \mathrm{ha}$ ) bordered by similar arable and pasture farmland. Miscanthus fields in both areas had uncultivated (but annually cut) 2-m grassy field margins as an entry-level agri-environment measure. The density of hares during 2007-2009 in the part of the study area which was almost entirely grassland, estimated using night time line-transect distance sampling, was 41.8 hares $\mathrm{km}^{-2}$, much higher than the regional average (Petrovan et al. 2011a), and together with other species, especially pheasants (Phasianus colchicus), hares were subject to commercial hunting on the site (Petrovan et al. 2011b). Hare density in the Miscanthus areas was unknown and the height of the crop would have meant such data could only have been collected in early spring.

\section{Data collection}

Hares were captured inside the Miscanthus fields in spring when the crop was short using a line of two to four beaters and two 100-m-long quick-set long nets (JB nets, UK) placed across openings in hedgerows and access points into the fields. Captured hares were immobilised, sexed and radiocollared with TW-3 cable-tie small mammal radio collars (Biotrack Ltd., Dorset, UK). The combined weight of the collar was less than $1 \%$ of the animal's body weight. All animals were released within 6-10 min of capture. Juveniles of less than $2 \mathrm{~kg}$ were not collared to avoid potential injuries as collars were not expandable. All procedures were carried out in accordance with the University of Hull Ethical Committee protocols and standards for non-licenced animal species. Radio-tracking was performed on foot using a Yagi antenna using homing-in as a technique in order to obtain high precision fixes (Petrovan et al. 2013). Fixes were collected with a minimum 3-h interval to obtain independence (Harris et al. 1990) and collected with one to four fixes per week during both day (inactive period) and night (active period) and during all four seasons. The active period extended from $1 \mathrm{~h}$ prior to sunset until $1 \mathrm{~h}$ after sunrise, while the inactive period extended from $1 \mathrm{~h}$ past sunrise until $1 \mathrm{~h}$ prior to sunset. 
Diet was assessed by collecting fresh hare droppings from both areas of Miscanthus fields and separated between seasons as spring, summer and winter. Hare droppings were located by searching a predetermined transect inside the Miscanthus crops and were easily distinguishable from other sympatric species such as rabbits (Oryctolagus cuniculus), based on their size, shape and appearance, with large observable plant fragments on the surface. At least 10 droppings from separate clumps located several meters away from each other were collected from each Miscanthus field to ensure a representative assessment of diet (Puig et al. 2007). Six combined samples obtained from hare droppings were analysed from each Miscanthus block in each of three seasons (winter, spring, summer), totalling 36 samples. Dried droppings were mixed with water and broken up with a spatula before sieving through $1.0 \mathrm{~mm}, 500 \mu \mathrm{m}$ and $250 \mu \mathrm{m}$ sieves, with the 500 and $250-\mu \mathrm{m}$ fractions retained for microhistological analysis. These separate fractions were cleared by boiling in $20 \%$ nitric acid solution for $3 \mathrm{~min}$ prior to staining and mounting using a Toluidine blue and glycerol solution following Katona and Altbäcker (2002). Plants were identified by comparison with a reference collection of plant epidermes of species found in the area, including of Miscanthus at different growth stages. Identifications were carried out using a Nikon Eclipse E400 compound microscope with $\times 10$ and $\times 40$ magnifications.

\section{Statistical analysis}

Hare home ranges were calculated using kernel density estimates with bandwidth estimated using smoothed cross-validation. In common with standard practice, $95 \%$ isopleths were defined as 'total' ranges and 50\% isopleths as 'core' ranges (Smith et al. 2004; Petrovan et al. 2013). Effects of sex, activity period and survey block on habitat use were assessed using repeated measures linear mixed models with individual hare as a random factor. Square root of number of fixes per range estimator was included in the model to account for potential variability in range size due to sampling effort. There were insufficient fixes per combination of individuals and factors to analyse multiple interactions of variables of interest. Analysis was therefore restricted to the three key variables: sex, activity and block as separate, non-interacting factors. Home range and habitat use
Fig. 1 Total (95\%) and core $(50 \%)$ home ranges and field use in both areas of Miscanthus. a Total (95\%) home ranges in the large block. b Total $(95 \%)$ ranges in the small block. c Core (50\%) ranges in the large block. $\mathbf{d}$ Core $(50 \%)$ home ranges in the small block
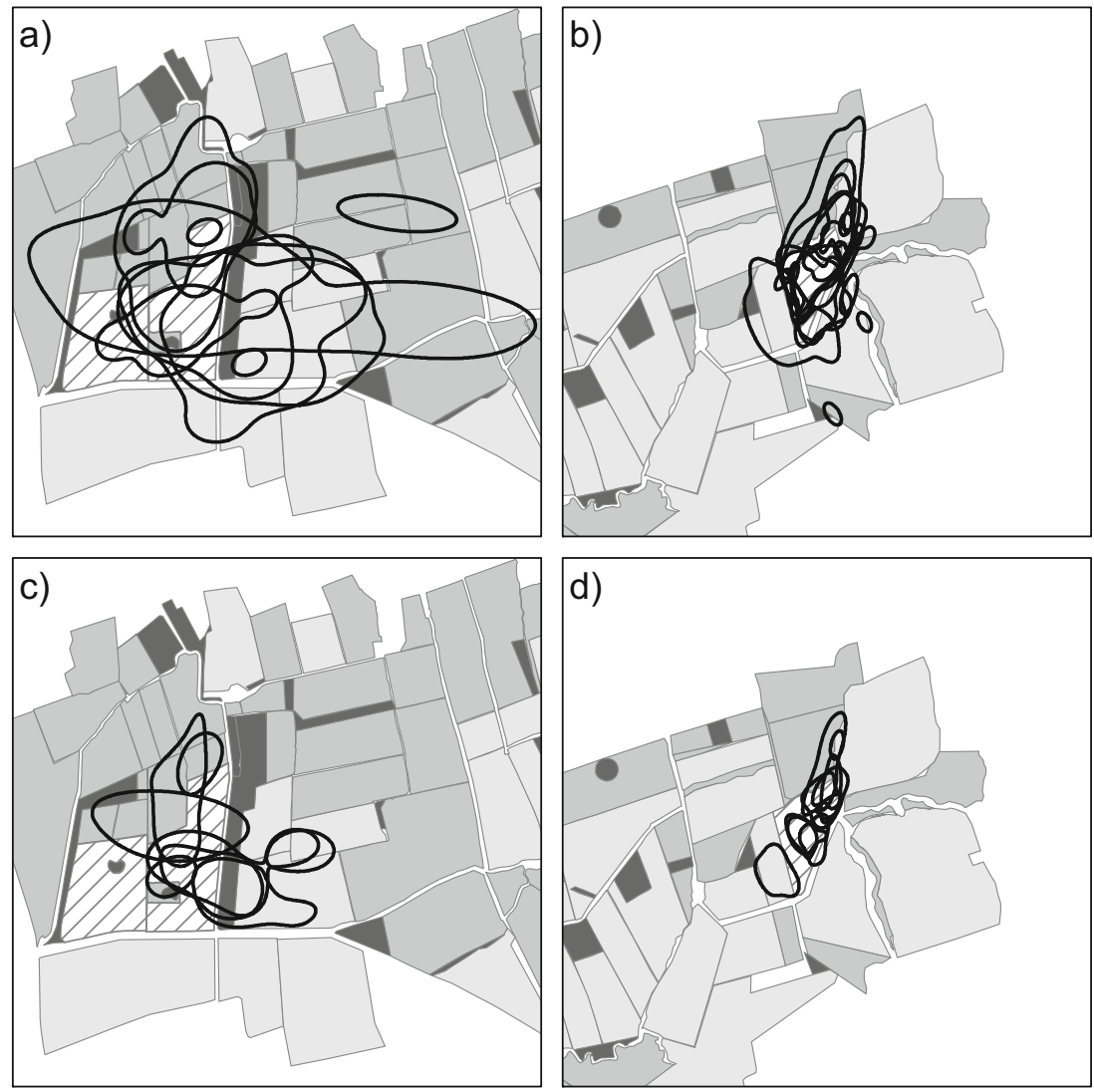

Land Use

Arable


Grassland Woodland/Plantation 
analysis was carried out using Geospatial Modelling Environment (Beyer 2012), ArcGIS 10.2 (ESRI 2014) and R 3.1.2 (R Core Team 2014). Further statistical analyses were carried out in R using package nlme (Pinheiro et al. 2015).

\section{Results}

A total of 17 hares, 10 males and 7 females, were tracked for between 4 and 11 months (median $=8$ months) in two periods between spring 2010 and spring 2012. Of these, seven animals (four males, three females) were associated with the large Miscanthus block and 10 others (six males and four females) with the small block (Fig. 1). A minimum of 18 and maximum of 50 fixes were recorded per animal $($ median $=43$ ). Previous radio-tracking of a larger number of hares at the site had demonstrated this was sufficient to adequately assess home ranges (Petrovan et al. 2013). A median of 18 fixes (range 7-25) was recorded in active periods, and a median of 24 fixes (range 9-32) was recorded in inactive periods (Table S1). It is possible that at the lower range, the small number of fixes used to estimate home ranges for active and inactive periods separately may have not generated stable range estimates. However, the lack of a significant effect of number of fixes in our models suggests that there was no systematic bias caused by this.

Neither 'total' (95\%, Fig. 2) nor 'core' (50\%, Fig. 3) ranges size differed significantly between males and females or between active or inactive periods (Table 1 and S1). There were no significant differences in the area of Miscanthus used as part of these home ranges between sexes (Table 1). However, hares used Miscanthus as part of their total ranges significantly more during their inactive than their active periods $\left(\operatorname{mean}_{\text {Inactive }}=8.6 \mathrm{ha}\right.$, s.d. $_{\text {Inactive }}=5.1 \mathrm{ha}$; mean $_{\text {Active }}=7.1$ ha, s.d. Active $=5.4$ ha), though this difference was not apparent for core ranges.

Home range size and area of Miscanthus within the home range differed significantly and substantially between the two blocks for both total and core ranges (Figs. 1, 2 and 3 and Table 1). Home ranges were almost five times larger in the large Miscanthus block than in the small for both total and core ranges (total ranges: mean $_{\text {Large }}=49.63$ ha, s.d. Large $=22.55$ ha, mean $_{\text {Small }}=10.54$ ha, s.d.Small 5.41 ha; core ranges:
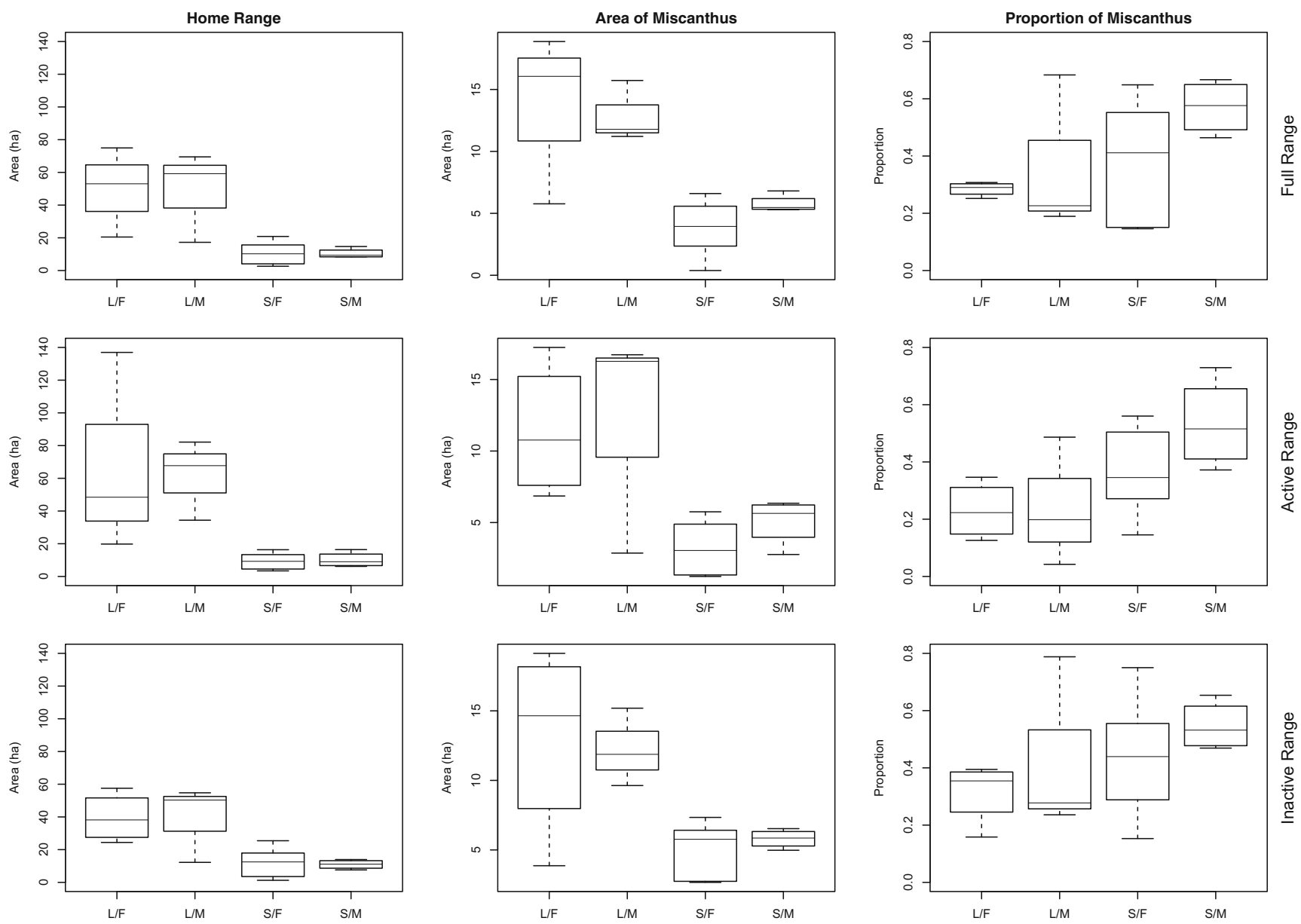

Fig. 2 Total (95\%) home ranges, area of Miscanthus in ranges and proportion of Miscanthus for full, active and inactive ranges by sex and block. $L / F$ large block, females; $L / M$ large block, males; $S / F$ small block, females; $S / M$ small block, males 

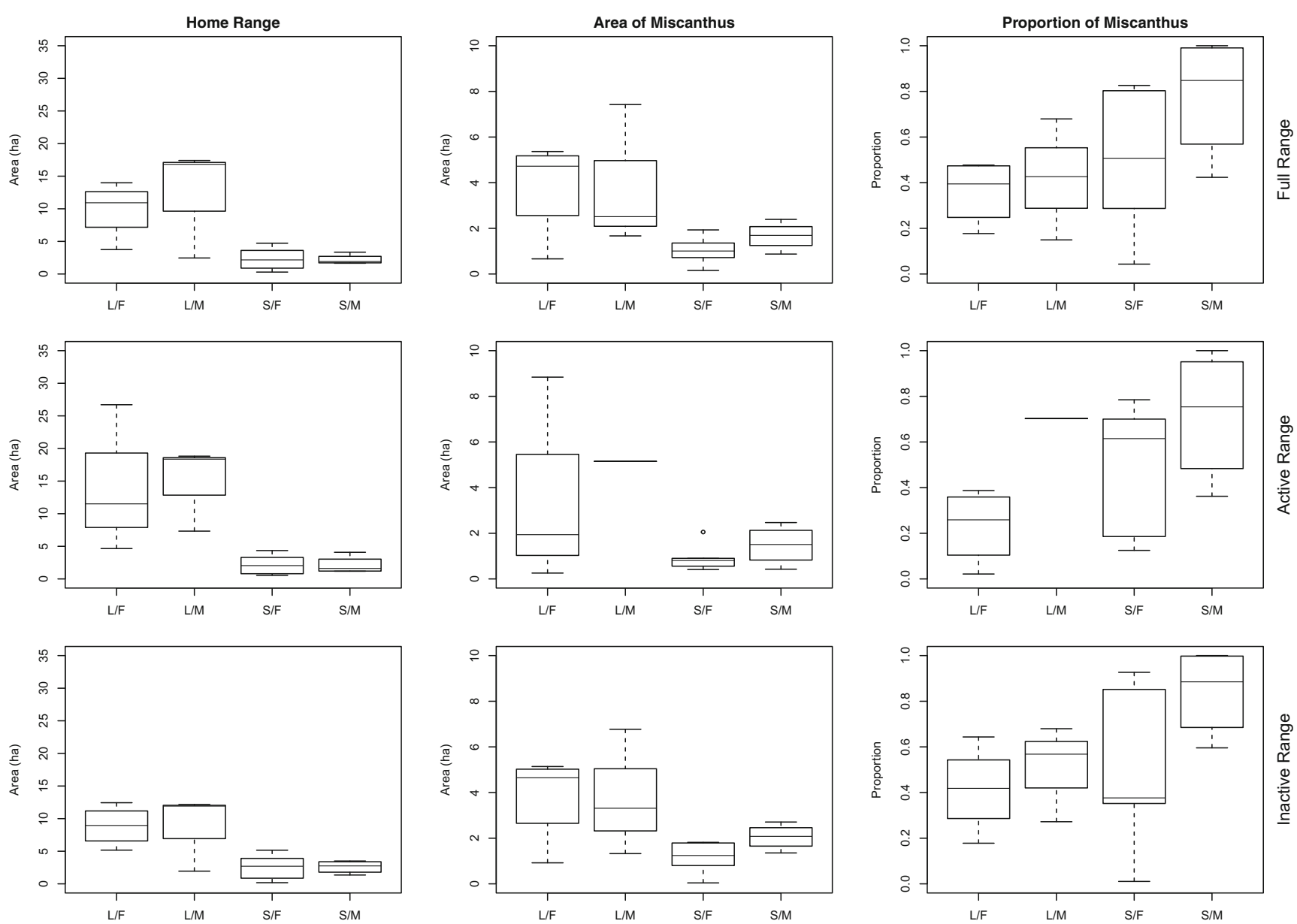

Fig. 3 Core (50\%) home ranges, area of Miscanthus in ranges and proportion of Miscanthus for full, active and inactive ranges by sex and block. $X$ axis labels as in Fig. 2

mean $_{\text {Large }}=10.89$ ha, s.d. Large $=5.91$ ha, mean $_{\text {Small }}=2.27$ ha, s.d. $_{\text {Small }}=1.31 \mathrm{ha}$ ). Hares used a larger area of Miscanthus in the large block than in the small block for both total and core ranges (total ranges: mean $_{\text {Large }}=13.64$ ha, s.d. Large $_{\text {. }}=4.37$ ha, mean $_{\text {Small }}=4.58$ ha, s.d. Small $=2.08$ ha; core ranges: mean $_{\text {Large }}=3.87$ ha, s.d. Large $=2.36$ ha, mean $_{\text {Small }}=1.31$ ha, s.d. Small $=0.69 \mathrm{ha})$. Miscanthus made up almost half of hare total ranges in the small block $\left(\right.$ mean $_{\text {Small }}=0.46$, s.d. .Small $\left.=0.19\right)$ and almost two thirds of their core ranges $\left(\right.$ mean $_{\text {Small }}=0.62$, s.d.Small $=0.33$ ). In the large block, almost one third of total ranges $\left(\operatorname{mean}_{\text {Large }}=0.32\right.$, s.d. Large $\left.=0.17\right)$ and slightly more of core ranges $\left(\right.$ mean $_{\text {Large }}=0.39$, s.d. Large $\left.=0.19\right)$ were inside Miscanthus crops. While the proportion of a hare's range composed of Miscanthus was generally greater in the small block for both total and core ranges, there was substantial variation and this difference was only just significant for total ranges and was not significant for core ranges.

No Miscanthus fragments were identified in hare droppings, indicating that even after the annual cutting and in its early growing stages in late spring, the plant remains unpalatable and avoided by hares, probably due to the very high lignocellulosic content and the availability of alternative food.
In all three studied seasons, hare diet in the area was comprised largely of wheat (Triticum aestivum) as well as a combination of grassland plants, especially meadow foxtail (Alopecurus pratensis), false oat grass (Arrhenatherum elatius), soft brome (Bromus hordeaceus) and Yorkshire fog (Holcus lanatus) (Table 2). While arable fields near the Miscanthus blocks were cultivated with wheat and oilseed rape (Brassica napus) at the time of our study, the grassland species in the hares' diet could be found in both adjacent improved pasture fields, in the grassy field margins of Miscanthus fields, as well as in the less dense patches occupied by Miscanthus itself. In the small block, hares were regularly observed feeding inside open patches of grassy vegetation where Miscanthus had partly failed.

\section{Discussion}

Adequate understanding of the impacts of bioenergy crops such as Miscanthus on farmland biodiversity is essential for ensuring the long-term sustainability of the crop and for preventing potential future conflicts. While several previous studies have 
Table 1 Output of repeated measures analysis on hare home ranges by block (large and small), sex (male and female) and activity (active and inactive)

\begin{tabular}{|c|c|c|c|c|c|c|}
\hline Total ranges & Factor & Value & SE & $d f$ & $t$ & $p$ value \\
\hline \multirow[t]{3}{*}{ Home range } & Block**** & -49.955 & 10.722 & 14 & -4.659 & $<0.001$ \\
\hline & Sex & -5.735 & 9.477 & 14 & -0.605 & 0.555 \\
\hline & Activity & 11.331 & 12.971 & 15 & 0.874 & 0.396 \\
\hline \multirow[t]{3}{*}{ Area of Miscanthus } & Block*** & -9.848 & 1.803 & 14 & -5.462 & $<0.001$ \\
\hline & Sex & -0.467 & 1.612 & 14 & -0.290 & 0.776 \\
\hline & Activity* & 5.908 & 2.220 & 14 & 2.662 & 0.019 \\
\hline \multirow[t]{3}{*}{ Proportion of Miscanthus } & Block* & 0.197 & 0.090 & 14 & 2.178 & 0.047 \\
\hline & Sex & 0.134 & 0.081 & 14 & 1.650 & 0.121 \\
\hline & Activity & -0.006 & 0.106 & 14 & -0.056 & 0.956 \\
\hline \multicolumn{7}{|l|}{ Core ranges } \\
\hline \multirow[t]{3}{*}{ Home range } & Block*** & -10.899 & 2.242 & 14 & -4.862 & $<0.001$ \\
\hline & Sex & -0.756 & 1.971 & 14 & -0.383 & 0.707 \\
\hline & Activity & 1.753 & 2.777 & 15 & 0.631 & 0.537 \\
\hline \multirow[t]{3}{*}{ Area of Miscanthus } & Block** & -3.316 & 0.798 & 13 & -4.156 & 0.001 \\
\hline & Sex & -0.033 & 0.761 & 13 & -0.043 & 0.966 \\
\hline & Activity & 2.379 & 1.209 & 12 & 1.967 & 0.073 \\
\hline \multirow[t]{3}{*}{ Proportion of Miscanthus } & Block & 0.246 & 0.140 & 13 & 1.761 & 0.102 \\
\hline & Sex & 0.260 & 0.132 & 13 & 1.974 & 0.070 \\
\hline & Activity & 0.019 & 0.167 & 12 & 0.114 & 0.911 \\
\hline
\end{tabular}

Number of fixes was included as a factor in all models but was not significant in any. Significant factors are indicated in bold and asterisked as follows: $* p<0.05, * * p<0.01, * * * p<0.001$ assessed patterns in biodiversity in Miscanthus crops, we have sought to understand how this novel crop affects the ecology of our target species, the brown hare. As expected for a species that prefers open areas for foraging, hares used Miscanthus fields more during daytime resting periods than for feeding at night when they selected nearby arable crops, such as wheat, and pastures. Hares are highly selective feeders (Schai-Braun et al. 2015), and we found no evidence that hares fed on the Miscanthus crop itself, including its very early growth stages. While there is extremely little data on herbivory from European mammals on Miscanthus, there is a suggestion that Meadow voles (Microtus pennsylvanicus) target and severely damage Miscanthus $\times$ giganteus seedlings (Hager and Stewart 2013).
The most striking result, however, is the fivefold difference in average hare home ranges between our Miscanthus study blocks. The home range sizes reported for the 10 hares tracked in the small Miscanthus field are, at an average of 10.54 ha across all four seasons, the smallest annual home ranges reported for this species in Europe and significantly smaller than the average for hares in the wider region (25.6 ha; Petrovan et al. 2013). The fact that such a mobile species, requiring landscape-scale habitat diversity (Vaughan et al. 2003; Smith et al. 2004) and which typically uses several fields over the course of the year, can maintain such apparent high density and small home ranges in the vicinity of the small Miscanthus block is strongly indicative that this crop can, in the right

Table 2 Diet composition from hare pellets collected from large and small Miscanthus blocks

\begin{tabular}{llllllll}
\hline Block & Season & $\begin{array}{l}\text { Triticum } \\
\text { aestivum }\end{array}$ & $\begin{array}{l}\text { Alopecurus } \\
\text { pratensis }\end{array}$ & $\begin{array}{l}\text { Arrhenatherum } \\
\text { elatius }\end{array}$ & $\begin{array}{l}\text { Bromus } \\
\text { hordeaceus }\end{array}$ & $\begin{array}{l}\text { Holcus } \\
\text { lanatus }\end{array}$ & $\begin{array}{l}\text { Lolium } \\
\text { perenne }\end{array}$ \\
\hline Large & Spring & 0.29 & 0.14 & 0.09 & 0.19 & 0.24 & 0.05 \\
repens
\end{tabular}

No plant epidermal fragments identifiable as Miscanthus were found 
conditions, provide highly suitable habitat for this species. By contrast, in the large Miscanthus block, hare home ranges were on average $49.6 \mathrm{ha}$, almost double the average for hares in the wider region, suggesting that dense and adjoining fields planted with this crop provide poor habitat for this species and might force them to feed at significant distances in nearby fields, with substantial costs in terms of energy expenditure. To some degree, this is similar as for the general increase in farmland field size observed in other studies, yet this crop is different in that it is never consumed by hares, is perennial and requires extremely limited management. The small Miscanthus block in this study is typical in area for fields reported from pastural parts of the UK but much smaller than those in arable areas (Robinson and Sutherland 2002). Recent UK government statistics (Defra, Government Statistical Service 2014) show that most Miscanthus planting is at a relatively large scale: $67 \%$ of UK production (by area) is by growers harvesting at least 20 ha, though whether these represent single large plantings or multiple small ones is not clear. One of the components of agricultural intensification which has driven losses in farmland biodiversity across Europe has been an increase in the scale of farming and its concurrent homogenisation (Donald et al. 2001). Large-scale planting of homogeneous Miscanthus crops would appear to present a similar threat to that of traditional crops.

Our results indicate that within farmland settings, the introduction of biomass energy crops, in particular Miscanthus, can have significant effects on the habitat use of a typical farmland species and, by extension, with potential implications on its density and abundance. We show that these effects are strongly linked with the planting scheme. In small blocks and as a component of mixed farming landscapes, Miscanthus might provide increased structural heterogeneity and areas of low mechanical and chemical input of particular importance at times of the year when such areas are scarce in intensively farmed landscapes (i.e. during winter or in late autumn when arable crops are harvested). However, these results would need additional replication in order to confirm their validity in diverse spatial settings. With evidence-based and targeted management which adequately takes into account biodiversity responses to such crops, it is likely that perennial biomass energy crops such as Miscanthus can be used to improve conditions for a range of farmland taxa while at the same time providing soil protection and a source of renewable energy.

Acknowledgements The study was generously funded and supported by the People's Trust for Endangered Species through a UK Mammals Grant. We are grateful to CEMS students and in particular Lucy Lush for their enthusiastic work and support during radio-tracking and diet analysis.

Open Access This article is distributed under the terms of the Creative Commons Attribution 4.0 International License (http:// creativecommons.org/licenses/by/4.0/), which permits unrestricted use, distribution, and reproduction in any medium, provided you give appropriate credit to the original author(s) and the source, provide a link to the Creative Commons license, and indicate if changes were made.

\section{References}

Bellamy PE, Croxton PJ, Heard MS, Hinsley SA, Hulmes L, Hulmes S, Nuttall P, Pywell RF, Rothery P. (2009) The impact of growing Miscanthus for biomass on farmland bird populations. Biomass Bioenergy 33:191-199. doi.org/10.1016/j.biombioe.2008.07.001

Benton TG, Bryant DM, Cole L, Crick HQP (2002) Linking agricultural practice to insect and bird populations: a historical study over three decades. J Appl Ecol 39:673-687. doi:10.1046/j.13652664.2002.00745.x

Beyer, HL (2012) Geospatial modelling environment (version 0.7.2.1). (software). URL: http://www.spatialecology.com/gme.

Bourke D, Stanley D, O’Rourke E, Thompson R, Carnus T, Dauber J, Emmerson M, Whelan P, Hecq F, Flynn E, Dolan L, Stout J (2014) Response of farmland biodiversity to the introduction of bioenergy crops: effects of local factors and surrounding landscape context. GCB Bioenergy 6:275-289. doi:10.1111/gcbb.12089

Clapham SJ (2011) The abundance and diversity of small mammals and birds in mature crops of the perennial grasses Miscanthus $\times$ giganteus and Phalaris arundinacea grown for biomass energy. Unpublished $\mathrm{PhD}$ thesis. Cardiff University. [Online]. Available at: http://orca.cf.ac.uk/15629/1/2011ClaphamSJPhD.pdf

Côté SD, Rooney TP, Tremblay JP, Dussault C, Waller DM (2004) Ecological impacts of deer overabundance. Annu Rev Ecol Evol Syst 35:113-147. doi:10.1146/annurev.ecolsys.35.021103.105725

Dauber J, Cass S, Gabriel D, Harte K, Åström S, O'Rourke E, Stout JC (2015) Yield-biodiversity trade-off in patchy fields of Miscanthus $\times$ giganteus. GCB Bioenergy 7(3):455-467. doi:10.1111/gcbb.12167

Department of Environment, Food and Rural Affairs, (Defra), Government Statistical Service (2014) Area of crops grown for bioenergy in England and the UK: 2008-2013. Available at: https://www.gov.uk/government/statistics/area-of-crops-grown-forbioenergy-in-england-and-the-uk-2008-2013

DECC (2012) UK bioenergy strategy. Department of Energy and Climate Change, London

Donald PF, Green RE, Heath MF (2001) Agricultural intensification and the collapse of Europe's farmland bird populations. Proc of the Royal Society of London B: Biological Sciences 268:25-29. doi:10.1098/rspb.2000.1325

ESRI (2014) ArcGIS desktop: release 10.2 Redlands, CA: Environmental Systems Research Institute.

Everaars J, Frank K, Huth A (2014) Species ecology and the impacts of bioenergy crops: an assessment approach with four example farmland bird species. GCB Bioenergy 6:252-264. doi: $10.1111 /$ gcbb. 12135

Hager HA, Stewart FE (2013) Suspected selective herbivory of bioenergy grasses by meadow voles (Microtus pennsylvanicus). The Canadian Field-Naturalist 127:44-49

Harris S, Cresswell WJ, Forde PG, Trewhella WJ, Woollard T, Wray S (1990) Home-range analysis using radio-tracking data- a review of problems and techniques particularly as applied to the study of mammals. Mammal Rev 20:97-123. doi:10.1111/j.1365-2907. 1990.tb00106.x

Katona K, Altbäcker V (2002) Diet estimation by faeces analysis: sampling optimisation for the European hare. Folia ZoologicaPraha 51:11-16

Pedroli B, Elbersen B, Frederiksen P, Grandin U, Heikkilä R, Krogh PH, Spijker J (2013) Is energy cropping in Europe compatible with biodiversity? - opportunities and threats to biodiversity from land- 
based production of biomass for bioenergy purposes. Biomass Bioenergy 55:73-86. dx.doi.org/10.1016/j.biombioe.2012.09.054

Petrovan SO, Ward AI, Wheeler PM (2011a) Detectability counts when assessing populations for biodiversity targets. PLoS One 6:e24206. dx.doi.org/10.1371/journal.pone.0024206

Petrovan SO, Barrio IC, Ward AI, Wheeler PM (2011b) Farming for pests? Local and landscape-scale effects of grassland management on rabbit densities. Eur J Wild Res 57:27-34. doi:10.1007/s10344010-0394-9

Petrovan SO, Ward AI, Wheeler PM (2013) Habitat selection guiding agri-environment schemes for a farmland specialist, the brown hare. Anim Conserv 16:344-352. doi:10.1111/acv.12002

Pinheiro J, Bates D, DebRoy S, Sarkar D, R Core Team (2015)._nlme: linear and nonlinear mixed effects models_. R package version 3.1-120, <URL: http://CRAN.R-project.org/package=nlme>.

Puig S, Videla F, Cona MI, Monge SA (2007) Diet of the brown hare (Lepus europaeus) and food availability in northern Patagonia (Mendoza, Argentina). Mammalian Biology - Zeitschrift für Säugetierkunde 72:240-250. doi:10.1016/j.mambio.2006.08.006

R Core Team (2014) R: a language and environment for statistical computing. R Foundation for Statistical Computing, Vienna, Austria. URL http://www.R-project.org/

Robinson RA, Sutherland WJ (2002) Post-war changes in arable farming and biodiversity in Great Britain. J Appl Ecol 39:157-176. doi:10.1046/j.1365-2664.2002.00695.x
Schai-Braun SC, Reichlin TS, Ruf T, Klansek E, Tataruch F, Arnold W, Hackländer K (2015) The European hare (Lepus europaeus): a picky herbivore searching for plant parts rich in fat. PLoS One 10: e0134278. doi:10.1371/journal.pone.0134278

Semere T, Slater FM (2007) Ground flora, small mammal and bird species diversity in Miscanthus (Miscanthus $\times$ giganteus) and reed canary-grass (Phalaris arundinacea) fields. Biomass Bioenergy 31:20-29. doi:10.1016/j.biombioe.2006.07.001

Smith RK, Jennings NV, Robinson A, Harris S (2004) Conservation of European hares Lepus europaeus in Britain: is increasing habitat heterogeneity in farmland the answer? J Appl Ecol 41:1092-1102. doi: 10.1111/j.0021-8901.2004.00976.x

Smith RK, Vaughan Jennings N, Harris S (2005) A quantitative analysis of the abundance and demography of European hares Lepus europaeus in relation to habitat type, intensity of agriculture and climate. Mammal Rev 35:1-24. doi: 10.1111/j.1365-2907.2005. 00057.x

Tscharntke T, Clough Y, Wanger TC, Jackson L, Motzke I, Perfecto I, Vandermeer J, Whitbread A (2012) Global food security, biodiversity conservation and the future of agricultural intensification. Biological Cons 151:53-59. dx.doi.org/10.1016/j. biocon.2012.01.068

Vaughan N, Lucas EA, Harris S, White PCL (2003) Habitat associations of European hares Lepus europaeus in England and Wales: implications for farmland management. J Appl Ecol 40:163-175. doi:10. 1046/j.1365-2664.2003.00784.x 